\title{
Perfect, Amicable and Numbers of Equal Weights (Historical Notes)
}

\author{
Falih A.M. Aldosray
}

Department of Mathematics, Umm Al-Qura University

Makkah, Saudi Arabia

email;fadosary@uqu.edu.sa.

\begin{abstract}
Amicable, Perfect, deficient and abundant numbers studied by many Arab sceintist including, Thabit Ibn Qurra, Kamal al-Din al-Farisi, Ibn Sina, abdul-Qahir al-Baghdadi, Ibn al-Banna al-Marakishi and others during the golden age of Islamic civilization.
\end{abstract}

Keywords: Keyword 01A30, Keyword11 Z99

\section{Perfect Numbers}

Let denote the sum of all the proper divisors of the natural number n. We say that $n$, is

(i) A perfect number, if $=n$.

(ii) A deficient number, if $<\mathrm{n}$.

(iii) A abundant number if $>n$.

Euclid thought up "perfect numbers", and same definition appear with Manajos (100m).

Example1:

8 is deficient number since $\sigma_{0}(8)=1+2+4<8$

12 is abundant number since $\sigma_{0}(12)=1+2+3+4+6>12$.

Note that Abdul Qahir Ibn Taher al-Baghdadi says in his manuscript ([3],Altakmila fi alhisab), that the first abundant number is 12, and all odd numbers less than 945 are deficient number, and the first odd deficient number is 945 .

Example2:

(i) 6 is a perfect number since $\sigma_{0}(6)=1+2+3=6$

(ii) 28 is a perfect number, since $\sigma_{0}(28)=1+2+4+7+14=28$

(iii) 496 is a perfect number, since

$\sigma_{0}(496)=1+2+4+8+16+31+62+124+248=496$

(iv) 8128 is a perfect number, since $\sigma_{0}(8128)=8128$

And these numbers appears with Minakhos (100m), but the following rule of detemining(finding) the perfect numbers:

If $\mathrm{S}_{\mathrm{p}}=\sum_{\mathrm{i}=1}^{\mathrm{p}} 2^{\mathrm{i}-1}$ is a prime number, then $2^{p-1} \times S_{p}$ is a perfect number, which 
appear in al-amili ${ }^{1}$ book "Khulaset Alhisab" and in" Nicomakhos: Introductin to Number Theory", Al Qubaisi paper "Sum of sepcial types of Numbers" and in [13], to Ibn al-Bana al-marakishi , AbdelQahir al-Baghdadi ${ }^{2}$ treatise al-Takmilafi'l-Hisab [3],and others belong to Euclid as Ibn Qurra(826901) says. Now we recall the following proposition with its proof from " Raf al-hijab(liftting the veil) an wijuh amal al-hisab ,[13],p106" to Ibn albana al-marakishi.

Proposition : If $S_{p}=\sum_{\mathrm{i}=1}^{\mathrm{p}} 2^{\mathrm{i}-1}=2^{\mathrm{p}}-1$ is a prime number, then

(i) $A=2^{p-1} \times S_{p}$ is a perfect number.

(ii) $B=2^{p} \times S_{p}$ is abundant number.

(iii) $C=2^{p-2} \times S_{p}$ is a deficient number.

Proof: Let $m=S_{p}$. Then

(i) Since $\sigma_{0}(A)=m\left(1+2+\ldots+2^{p-2}\right)+\left(1+2+\ldots+2^{p-1}\right)$

$=\mathrm{m}\left[1+2+\ldots+2^{\mathrm{p}-2}+1\right]=\mathrm{m}\left[2^{\mathrm{p}-1}-1+1\right]=\mathrm{m} \times 2^{\mathrm{p}-1}=\mathrm{A}$

Hence $\mathrm{A}$ is a perfect number.

(ii) Since $\sigma_{0}(B)=m\left(1+2+\ldots+2^{p-1}\right)+\left(1+2+\ldots+2^{p-1}\right)+2^{p}$

$=\mathrm{m}^{2}+\mathrm{m}+2^{\mathrm{p}}=\mathrm{m}(\mathrm{m}+1)+2^{\mathrm{p}}=2^{\mathrm{p}} \times \mathrm{m}=\mathrm{B}+2^{\mathrm{p}}>\mathrm{B}$

Hence B abundant number.

(iii) Since $\sigma_{0}(C)=\left(m \times 2^{p-2}\right)-2^{p-1}=C-2^{p-1}<C$. Hence $\mathrm{C}$

is deficient number.

According to the perfect numbers Rule:

6 is the first perfect number,since $S_{2}=3$ is prime and 2(3)=6.

28 is the second perfect number, since $S_{3}=7$ is prime and

$$
28=2^{2} \times \mathrm{S}_{3}=4 \times 7 .
$$

The third perfect number is 496 , since $S_{5}=31$ is prime, and

$496=2^{4} \times \mathrm{S}_{5}=16 \times 31$

The fourth perfect number is 8128 , since $S_{7}=127$ is prime, and

$8128=2^{6} \times S_{7}=64 \times 127$.

$S_{13}=2^{13}-1=8191$ The fifth perfect number is 33550336 , since $S_{13}=2^{13}-1=8191$

is prime, and $2^{12} \times S_{13}=4096 \times 8191=335500336$.

\footnotetext{
$\left.{ }^{1}\right)$ al-Amili : Bahaa Eddin Mohammed Ibn Hussein bin Abdul Samad Al-Harthy, born Baalbek year ( 953 AH ), and died in Isfahan in $1031 \mathrm{AH}$, Mathematician, astronomer and writer . The most famous writings : Khlast Alhesab( account summary), Anatomy of the universe, A message in Alostrlabah , message in algebra and almuqabla.
} 
$\mathrm{S}_{17}=2^{17}-1=131071$ The sixth perfect number is 8589869056 , since

is prime, and $65536 \times 131071=8589869056$.

We Knew now 27 perfect numbers when the prime number

$$
p \in\left\{\begin{array}{l}
2,3,5,7,13,17,19,31,61,89,107,257,521,607,1279,2203,2281, \\
3217,4253,4423,9689,9941,11213,19937,21701,23209,44497
\end{array}\right\}
$$

Finally, we would like to point out that Abdul-Qahir al-Baghdadi said in his book (,[3], Altakmula fil alhisab) that: " it is a mistake if you said that one is a perfect number , and it is true that each perfect number must be at the beginning of six or eight ". Then he mension the previous rule of costruction perfect numbers and he suggest the, following rule, which states:

$$
\text { If } \sigma_{0}\left(2^{n}\right)=2^{n}-1
$$

is a prime number, then $\left[1+2+3+\ldots+\left(2^{\mathrm{n}}-1\right)\right]$ is a perfect number.

According to al-Baghdadi Rule we find that 6 is the first perfect number, 28 is the second perfect number, 496 is the third perfect number,and so on. In his Analysis and Synthesis, Ibn al-Hythem,[19], may have been the first to state that every even perfect number is of the form $2^{n-1}\left(2^{n}-1\right)$ where $2^{n}-1$ is prime, but he was not able to prove this result successfully (Euler later proved it in the 18th century).

\section{AMICABLE Numbers}

We say that the natural numbers $m$ and $n$ are amicable if $\quad \sigma_{0}(n)=m$ and $\sigma_{0}(m)=n$

Amecable numbers are defined by Pythagoras. According to this definition 220and 284 are amicable,since :

$$
\begin{aligned}
& \sigma_{0}(220)=1+2+4+5+10+11+20+22+55+110=284 \\
& \sigma_{0}(284)=1+2+4+71+142=220
\end{aligned}
$$

and the discovery of this pair go back to Pythagoras.

The following Rule is attributed to Thabit Ibn Qurra al-Harrani ${ }^{2}$, [6,8,21]

Let $a, b$ and $c$ be distinct prime numbers given by

$$
a=3 \times 2^{n-1}-1 \quad b=3 \times 2^{n}-1, c=9 \times 2^{2 n-1}-1
$$

Where $n$ is greater than 1, then $\mathrm{D}=2^{\mathrm{n}} \times \mathrm{ab}, \mathrm{E}=2^{\mathrm{n}} \times \mathrm{c}$ will be a pair of amicable numbers, $\mathrm{D}$ is an abundant number while $\mathrm{E}$ is a deficient number.For $n=2, \mathrm{a}=11, \mathrm{~b}=5, \mathrm{c}=71$ are all prime numbers, so $\mathrm{D}=2^{2} \times 5 \times 11=220, \mathrm{E}=2^{2} \times 71=284$, which is the smallest pair of amicable numbers.

J. P. Hogendijk (1985) pointed out that Thabit carried through his proof of his theorem for the case when the parameter $n=7$ which indicates that Thabit knew the amicable pair 17,296 and 18,416 (the

\footnotetext{
$\left.{ }^{2}\right)$ Thābit ibn Qurra al-Ḥarāānī( 826 -901) was an Arabic mathematician, physician, astronomer, and translator of the Islamic Golden Age who lived in Baghdad in the second half of the ninth century during the time of Abbasi Caliphate.Ibn Qurra made important discoveries in algebra, geometry, and astronomy. In astronomy, Thabit is considered one of the first reformers of the Ptolemaic system, and in mechanics he was a founder of statics. Thabit generalised Pythagoras's theorem to an arbitrary triangle (as did Pappus). He also discussed parabolas, angle trisection and magic squares. Thabit's work on parabolas and paraboliods is of particular importance since it is one of the steps taken towards the discovery of the integral calculus. An important consideration here is whether Thabit was familiar with the methods of Archimedes. Most authors believe that although Thabit was familiar with Archimedes' results on the quadrature of the parabola, he did not have either of Archimedes' two treatises on the topic. In fact Thabit effectively computed the integral of $\sqrt{ } x$ and the computation is based essentially on the application of upper and lower integral sums, and the proof is done by the method of exhaustion: there, for the first time, the segment of integration is divided into unequal parts.
} 
amicable numbers produced for $n=4$ ). Amicable numbers has been studied in the second half of the tenth century by Abu Saqr al-Qubaisi ${ }^{3}$, in his article (Sum of special types of numbers) [6,12],stating Ibn Quarra Theorem as follows:

If

$a=\left(2^{n+1}-1\right)+2^{n}, b=\left(2^{n+1}-1\right)-2^{n-1}, c=2^{n+1}\left(2^{n+1}+2^{n-2}\right)-1$, are prime numbers, then

$\mathrm{D}=2^{\mathrm{n}} \times \mathrm{ab}, \mathrm{E}=2^{\mathrm{n}} \times \mathrm{c}$ will be a pair of amicable numbers.

Al Karkhi ${ }^{4}$ also singled out in his book ( Badi fil alhisab ),[9], chapter on the amicable numbers proving Ibn Qurra theorem and concludes the following: If D,E is a pair of amicable numbers, then it is nescerly that one of them is an abundant number and the other is a deficient number,

E- $\sigma_{0}(E)=\mathrm{D}-\sigma_{0}(D)$. Then he prove the following: If $a=3 \times 2^{n-1}-1$

$b=3 \times 2^{n}-1, c=9 \times 2^{2 n-1}-1$ are odd prime numbers and

$c>\sigma=\sum_{r=0}^{n} 2^{r}, c-\sigma=(1+a+b) \sigma-a b$, then $\mathrm{D}=2^{\mathrm{n}} \times \mathrm{ab}, \mathrm{E}=2^{\mathrm{n}} \times \mathrm{c}$ is a pair of amicable

numbers, ,D is an abundant number while $\mathrm{E}$ is a deficient number.

Ibn Sina ( 980-1037m ), has mentioned in his book ( healing : naturalist ),[26], the following:

If $2^{n+1}-1, \mathrm{~b}=3 \times 2^{\mathrm{n}-1}-1, \mathrm{a}=3 \times 2^{\mathrm{n}}-1$, are prime numbers,

then $, 2^{n}(a+b+a b)=2^{n}\left(9 \times 2^{n-1}-1\right), 2^{n} a b$ is a pair of amicable numbers. If we add that $\left(9 \times 2^{n-1}-1\right)$ is a prime number,we get Ibn Qurra Theorem with overload condition $2^{n+1}-1$, is prime.

Note that al-Zanjani (d. 1257 ) reinstated in his research (umdat alhisab) al-Baghdadi results and gave Ibn Qurra Theorem about amicable numbers, while Kamal al-Din al-Farisi ${ }^{5}$ prove, in his article (tathkirt al-ahbah fi tamam altahab) [4,6], Ibn Qurra Theorem, and identify the two amicable numbers 17,296 and 18,416 in the case of $\mathrm{n}=4$, and Ibn Hidor Tadili (d. 1413 AD) identify the same

\footnotetext{
${ }^{3}$ ) al-Qubaisi : Abdulaziz bin Osman al-Hashemi, astronomer and mathematician writers and poets, attributed to Qusaybah or near Samarra, Mosul. He wrote the book "The entrance to the industry the provisions of the Stars".
}

4 Al Karkhi (Alkrgi): Abu Bakr Muhammad ibn al-Hasan was born in Karkh from the outskirts of Baghdad, lived and put the most important production in Baghdad at the end of the tenth and the begining of Eleventh century.He has spent apart of his life in the mountainous areas, where he worked in engineering, this work appeare in his book "About drilling of wells,.He "died in Baghdad in (421 AH = 1020 AD), considered by some as one of the greatest Mathematician who have had a real impact in the progress of Mathematical Sciences, he has several books, including: a book in the Indian account, which speaks for the extraction approximate polynomial roots, and a book in the induction, and Alkafi book which contains rules of the product signs and unknowns, sums of the Algebraic terms and the laws of the last term and the total sum in numerical sequence, and the square root of Algebraic amounts. while in his book Alfkhry in algebra he study many problems, he is the first Arab proved that $(a+b)^{n}=\sum_{r=0}^{n}\left(\begin{array}{c}n \\ r\end{array}\right) a^{n-r} b^{r}$ and $\left(\begin{array}{c}n \\ r\end{array}\right)=\left(\begin{array}{c}n-1 \\ r-1\end{array}\right)+\left(\begin{array}{c}n-1 \\ r\end{array}\right)$.In his book 'Ellal Algeber wa almukabla" and, in het set out rules to solve the equations of the second degree as well as multiplication and division and addition and subtraction rules formulas for two rational numbers and proved those rules algebraically.

$\left.{ }^{5}\right)$ Kamal al-Din Hasan Ibn Ali ibn Hasan al-Farisi (1267-1319) was a prominent Muslim scientist. His work on optics was prompted by a question put to him concerning the refraction of light. Al-Farisi made a number of important contributions to number theory. His most impressive work in number theory is on amicable numbers. In Tadhkira al-ahbab fi bayan al-tahabb ("Memorandum for friends on the proof of amicability") introduced a major new approach to a whole area of number theory, introducing ideas concerning factorization and combinatorial methods. In fact Farisi's approach is based on the unique factorization of an integer into powers of prime numbers. 
pair. Al-Farisi was not satisfied just to give the calculation of "Fermat's couple" but stated a complete justification for it as well. He started with $\mathrm{n}=4$, then from Thabit's formula he gets:

$$
a=3 \times 2^{3}-1=71, b=3 \times 2^{4}-1=47, c=9 \times 2^{7}-1=1151
$$

The first two numbers are obviously primes, and he used several propositions to show that 1151 is a prime number. To prove that Fermat's couple is really a couple of amicable numbers, al-Farisi proceeded as follows:First recalling the definitions

For a natural number $n$ the sum of its proper (excluding $n$ ) divisors is $\sigma_{0}(n)$ so that: $\sigma(n)=\sigma_{0}(n)+n$.

By considering all the possible proper divisors of the number $2^{k} p$ where $p$ is a prime number or a product of prime numbers we can note that the sum of all the possible divisors of $2^{k} p$ is:

$$
\sigma\left(2^{k} p\right)=\sum_{r=0}^{k} 2^{r} \sigma(p)
$$

They can be rewritten through the following steps into a calculation with smaller numbers to work with:

$$
\begin{aligned}
& \sigma_{0}\left(2^{k} p\right)=\sigma\left(2^{k}\right) \sigma(p)-2^{k} p=\left[\sigma_{0}\left(2^{k}\right)+2^{k}\right]\left[\sigma_{0}(p)+p\right]-2^{k} p \\
& =\sigma_{0}\left(2^{k}\right) \sigma_{0}(p)+\sigma_{0}\left(2^{k}\right) p+2^{k} \sigma_{0}(p)=\sigma_{0}\left(2^{k}\right)\left[\sigma_{0}(p)+p\right]+2^{k} \sigma_{0}(p) \\
& \sigma_{0}\left(2^{k} p\right)=\sigma_{0}\left(2^{k}\right) \sigma(p)+2^{k} \sigma_{0}(p)
\end{aligned}
$$

This formula was used by al-Farisi to verify the amicable number pair 17,296 and 18,

$$
\begin{aligned}
& \sigma_{0}(17296)=\sigma_{0}\left(2^{4} .23 .47\right)=\sigma_{0}\left(2^{4}\right) \sigma(23.47)+2^{4} \sigma_{0}(23.47) \\
& =15(71+1081)+16(71)=18416, \\
& \sigma_{0}(18416)=\sigma_{0}\left(2^{4} .1151\right)=\sigma_{0}\left(2^{4}\right) \sigma(1151)+2^{4} \sigma_{0}(1151) \\
& =15(1+1151)+16(1)=17296
\end{aligned}
$$

Then, in the early 1600s, Muhammad Baqir Yazdi ${ }^{6}$, identified,[8], the two amicable numbers $9,363,584$ and 9,437,056 in the case of $n=7$ in Thabit's Theorem..

The discovery of the two couples of amicable numbers (17,296 and 18,416); (9,363,584 and $9,437,056)$ is usually attributed to Fermat and Descartes.But it has been recently shown that Fermat's couple had been calculated by an earlier Moroccan mathematician, Ibn al-Banna ${ }^{7},[13,14,20]$, who calculated it at least a century earlier. This mathematical result was subsequently known to many mathematicians, as was the case for the so called " Descartes couple.

Finally, we would like to point out that the Swiss mathematisian Leonard Euler (1707-1783) generalize Ibn Qurra Theorem, and discovered during (1747-1750) Fifty-nine pairs of amicable numbers including $(2924,2620),(5020,5564),(10856,10744),(6863,6232)$.

The pair ( 1210,1184) which can not be obtained by applying Ibn Qurra theorem discovered in 1867 by Italian Nicola Bagnini. They discovered so far 360 pairs of amicable numbers

\footnotetext{
${ }^{6}$ ) Muhammad Baqir Yazdi (d.AH1049/1639AD) was an Iranian mathematician who lived in the 16th century. He gave in major book is Oyoun Alhesab, the pair of amicable numbers 9,363,584 and 9,437,056 many years before Euler's contribution to amicable numbers.

${ }^{7}$ ) Ibn al-Banna al-Marrakishi ( 654=1256-721h=1321 ) Ahmed Ibn Mohammed Ibn Othman al-Azdi, Abu Abbas, was born in Marrakesh, his father was builder, excelled in mathematics, astronomy and has many books among them :Talkhes aemal alhisab, and the message in the weights, and part of the space, and the book in the stars, and an article in the science of the astrolabe, and the law to know the times by calculation(Arithmetic).
} 


\section{NUMBERS OF EQUAL WEIGHTS:}

These numbers introduced by al- Baghdadi [3], who define them as follows:Two natural numbers $\mathrm{m}$ and $\mathrm{n}$ are called of the same weight,if $\sigma_{0}(m)=\sigma_{0}(n)$.

Example: 39 and 55 are of equal weights, since $\sigma_{0}(39)=1+3+13=\sigma_{0}(55)=1+5+11$

Note that al-Baghdadi said, if a natural number $n$ is given, and it is required to find all numbers of equal weights whose the sums of its proper divisors is equal $n$ write $n=1+p_{i}+q_{i}$, where $p_{i}, q_{i}$ are distinct prime numbers ,then $\left\{p_{i} \times q_{i}\right\}$ are numbers of equal weights, and al-Baghdadi gives the following example:If $\mathrm{n}=57$, then $p_{1}=3, q_{1}=53, p_{2}=13, q_{2}=43$, and

$$
m=p_{1} \times q_{1}=159, n=p_{2} \times q_{2}=559
$$

are numbers of equal weights, since. $\sigma_{0}(159)=1+3+53=\sigma_{0}(559)=1+13+43=57$

Note that al-Zanjani in" umdat al-hisab" gave, the same definition and the same example proving that $159,559,703$ are numbers of equal weights, since. $\sigma_{0}(703)=1+19+37=57$.

Then we find a study of numbers of equal weights in many computational research. Mohammed Baqir Yazdi identify the following relationship:

If $2^{r}=p_{1}+q_{1}=p_{2}+q_{2}$, where $p_{1}, q_{1}, p_{2}, q_{2}$ are distinct prime numbers, then

$$
\begin{aligned}
& m=p_{1} \times q_{1}, n=p_{2} \times q_{2} \text { are numbers of equal weights, since } \\
& \sigma_{0}(m)=1+p_{1}+q_{1}=\sigma_{0}(n)=1+p_{2}+q_{2}=1+2^{r} .
\end{aligned}
$$

Example: If $r=5$,then , $2^{5}=32=3+29=13+19$ and $m=3 \times 29=87, n=13 \times 19=247$ are numbers of equal weights

\section{Conclusion}

The above works shows that the Arabic scientific tradition played a pioneering role in Number Theory, as it was the case also in other areas of mathematics.

\section{REFERENCES}

[1] F. A.M. Al-Dosray: Introduction to Mathematics Islamic civilization and its applications - Safa Press, 2003.

[2] A. A. Al-Daffa" Nawabigh ulama al-Arab wa-al-Muslmin fi al-riyadiyat."John Wiley and Sons, Inc.(1978).

[3] Abu Mansour Taher Abdul Qahir al-Baghdadi: "Al-takmula fi alhisab with the message in the area "Arab Research Institute: Kuwait 1980.

[4] Kamal al-Din al-Farisi:"Tatkirat al-ahbab fi tamam al-tahab" Script Laleli Sulaymaniyah Istanbul 1/2708.

[5] R. Akkaoui : Hassan Ibn al-Haytham, Gbm Ptolemy Althani, Dar alfiker Alarabi , Beirut 1997

[6] Berggren J.L. History of Mathematics in the Islamic World: The Present State of The Art. Middle East Studies Association Bulletin 19 (1985), pp. 9-33.

[7] COSTEllO, P. J. 'NEW AMICABLE PAIRS OF TYPE (2; 2) AND TYPE (3; 2) MATHEMATICS OF COMPUTATION, Volume 72, No 241, pp 489-497 (2002).

[8] L. Dikson, "History of the Theory of Numbers" Vols I, II , III, Chelsea

[9] Hogendijk, J. P. "Thabit ibn Qurra and the pair of amicable numbers 17296, 18416", Historia Mathematica, vol. 12 (3) (1985), pp. 269-273.

[10] Abu Bakir Muhammad al-Karkhi , "Al-Badi fi Alhisab" authenticated by Adel Enbuba , Beirut, the Lebanese University, 1964 .

[11] Abu Bakir Muhammad al-Karkhi “Alkafi fi Alhisab" Explanation and authenticated by S. 
Shalhoub ,Haleb University, 1986.

[12] Abu Hassan al- Kulsadi, "explain to summarize Al-hisab acts" translated into French by Fares bin Taleb, DMI West, 1999.

[13] Ibn al-Banna al- Marrakeshi "Raf al-hijab(liftting the veil) an wujuh amal al-hisab" Forward, study and investigation, by Dr. Mohamed Iblakh, publications Faculty of Arts and Sciences, Fass.

[14] Ibn al-Banna al-Marrakeshi, "Al-maqalat fi ilm al-hisab(articles in Arithmetic)"” a historic and comments of Dr. A. S. Saidan and Introduction, Dar Al-Furqan for publication 1984.

[15] G. al-Kashi, "Miftah Alhisab" authenticated, A. S. Eldemerdash and M. H. Hefny Al-Sheikh, Dar Al Arab writers for printing and publishing, 1967

[16] H. A. Al-Tayar and Y. Eid Saaid, "A Brief History of Mathematics": Mosul University, 1977.

[17] O. Farukh, "History of Science at the Arabs", House of science to millions, Beirut, 1914.

[18] M. Charbel, "Mathematics in the Islamic civilization" Groy Bri Tripoli, Lebanon. 1988 m. 84.

[19] J. J. O'Connor;and E. F. Robertson," “Abu Ali al-Hasan ibn al-Haytham”" MacTutor History of Mathematics archive, University of St Andrews

[20] J. Okasha, H. Abu Awad, M. Asaad and S. Abu Ali, "History of Mathematics" Future House of Publishing and Distribution, Amman 1990.

[21] R. Rashed, "Arab mathematics history between algebra and arithmetic" the Center for Arab Unity Studies, Beirut, 1989.

[22] R. Rashed, "The Development of Arabic Mathematics: between arithmetic and algebra". Dordrecht: Kluwer. 1994.

[23] A. S.Saidan, (1970). "al-Umawī, Abū Abdallāh Ya'īsh Ibn ibrāHīm Ibn Yūsuf Ibn Simāk AlAndalusì”". Dictionary of Scientific Biography. New York: Charles Scribner's Sons.

[24] A. S. Saidan (ed.), Yaish ibn Ibrahim al-Umawi, "On arithmetical rules and procedures" (Aleppo, 1981).

[25] J. Shawqi, “Al-aemal alriyathiah li- Bahauddin al-Amili” Sunrise House.1981.

[26] Ibn Sina, "healing - naturalist" authenticated by Abdel Hamid Lotfy Madher, Egyptian Authority for printing Cairo 1975.

[27] D. E. Smith, "History of Mathematic", Gins and company.

[28] A. Solomon and S.Hallaq, "Studies in the History of Science at Arab"university knowledge House 1998.

[29] K. H. Toukan, "Arab scientific heritage in mathematics and astronomy", Dar Alsuroq Beirut. 